\title{
POSDEMOCRACIA Y DICTADURA TECNOFINANCIERA LA TIRANÍA DE LOS MERCADOS OMNIPOTENTES
}

\author{
Jorge Polo Blanco \\ Universidad Complutense de Madrid
}

\begin{abstract}
Resumen.- En este trabajo queremos explorar algunas de las causas e implicaciones del autoritarismo de mercado, que incluso deviene en fórmulas más agresivas de lo que se ha dado en llamar fascismo financiero, toda vez que los mercados se institucionalizan en dinámicas autónomas democráticamente incontrolables que producen inevitablemente fenómenos crecientes de severa desdemocratización. En efecto, la legalidad cada vez más omnipotente de los mercados convierte a la economía privada en un espacio tiránico que escapa cada vez con mayor facilidad a la fiscalización política democrática. En ese escenario las finanzas se erigen en un poder fácticamente constituido que, lejos de someterse a la legalidad política de las instituciones democráticas, imponen su propia dinámica imperativa.
\end{abstract}

Palabras clave.- autoritarismo de mercado, despolitización de lo económico, fascismo financiero.

\begin{abstract}
In this work we want to explore some of the causes and implications of market authoritarianism, also transformed into more aggressive formulas dubbed financial fascism since markets are institutionalised in democratically uncontrollable autonomous dynamics, inevitably producing the growing phenomena of severe de-democratisation. As a result, the increasingly more omnipotent legality of the markets becomes a private economy in a tyrannical space that avoids, with even greater ease, democratic fiscal policy. In this setting finances are factually constructed with power that, far from being subjected to the political legality of democratic institutions, imposes its own imperative dynamic.
\end{abstract}

Keywords.- market authoritarianism, economic depoliticisation, financial fascism.

\section{Despolitización de lo económico en la era de los mercados indomeñables}

El historiador alemán Karl Dietrich Bracher explicaba que un criterio importante para diferenciar formas genuinas de totalitarismo de otras formas de dictadura o régimen autoritario lo proporciona el nivel de intensidad con el que el Estado controla y prefigura la vida privada de los ciudadanos, esto es, el grado de intensidad con el que un todopoderoso y macrocéfalo aparato estatal determina hasta el último átomo de la existencia civil de los individuos:

El régimen exige, de manera completamente abierta y afirmativa, la politización de todos los campos de la vida, y su éxito en la realización de esta parte del control totalitario [...] demuestra la capacidad del régimen para realizar su meta de la fusión total del Estado y la sociedad, del partido y el pueblo, del individuo y lo colectivo, en el ideal de la unidad total (1983: 57).

Nosotros, en cambio, queremos partir ahora de otra premisa, a saber, que un régimen sustentado en la despolitización extrema también es una forma de totalitarismo. Y, precisamente, la forma contemporánea de despolitización con mayor vigencia y potencia en las sociedades occidentales contemporáneas es aquélla que atañe a la esfera socioeconómica y que se despliega en los términos de un autoritarismo de mercado que implica, a su vez, la des-democratización de múltiples ámbitos de la existencia personal y colectiva. 
Ya al final de su magna obra Hannah Arendt explica que el totalitarismo puede emerger en un terreno social descompuesto y fragmentado en el que los sujetos, previamente atomizados y desconectados de toda inserción en el mundo de los asuntos comunes, apenas pueden desde su aislamiento ejercer una acción participativa en la vida pública:

Los Gobiernos totalitarios, como todas las tiranías, no podrían ciertamente existir sin destruir el terreno público de la vida, es decir, sin destruir, aislando a los hombres, sus capacidades políticas (1998: 576).

Destruida la esfera pública, y reducidas las gentes comunes a su condición de meros productores desconectados de toda participación activa en la resolución de los asuntos comunes, se asiste a un proceso eminente de despolitización. Hemos de pensar ahora, empero, si una de esas "tiranías despolitizadoras" de las que hablaba Arendt no puede hallarse también en el devenir del autoritarismo de mercado propio de las sociedades contemporáneas.

El empobrecimiento del vínculo social y político aparece también como efecto de la exacerbación maximalista del sistema de mercado, en un proceso que progresivamente ha ido subsumiendo los resortes más vitales de la sociedad humana en un mecanismo económico independizado, tendencialmente omnímodo y prácticamente incontrolable. La política ya apenas decide nada, anulada por la omnipotente legalidad de un sistema económico crecientemente autónomo. Aunque, bien es cierto, a tal sistema le puede seguir estorbando incluso la institucionalidad democrática más porosa y anémica:

No deja de ser curioso, y desde luego preocupante, que a pesar de que nuestras democracias sean ya tan débiles y poco capaces de enfrentarse a estos otros poderes, estos últimos no dejen de acorralarlas. Incluso siendo casi impotentes frente a ellos, resultan molestas para los grandes poderes económicos y financieros, y parece que han decidido tomarlas al asalto y asumir ellos mismos las riendas de los poderes públicos (Navarro, Torres López: 2012: 23).

Los poderes financieros controlan gobiernos dictando las políticas que éstos aplican con suma obediencia, o incluso participan directamente en los ejecutivos, vigilando férreamente que ninguna decisión pueda sobrepasar los límites de la ortodoxia económica.

Pero en un marco semejante, definido por la existencia de una serie de límites infranqueables, que lo son precisamente porque sobre ellos no puede siquiera disputarse o discutirse, derivamos hacia una merma creciente de la sustancia democrática. Las instituciones financieras internacionales que diseñan las pautas estructurales de las políticas económicas nacionales rebasan a una velocidad inasible los marcos políticos de influencia democrático-popular, y representan instancias no electas pero intensamente empoderadas que desembocan en explícitas situaciones de autoritarismo (Petras: 1999). Asistimos a una progresiva esclerotización de la instancia política, en lo que a la regulación de la vida socioeconómica se refiere. Porque esas zonas imponderables y oscuras, opacas para la determinación democrática, son espacios cada vez más amplios que, además, constituyen ámbitos decisivos para la integración y ordenación de la vida social.

Los dogmas de la doctrina económica liberal constituyen un consenso indiscutible. $\mathrm{Y}$, por eso mismo, tales dogmas escapan al foco de la disputa y se convierten, por el contrario, en el marco de toda discusión posible. Pero los marcos mismos jamás se 
discuten. Como bien señala Chantal Mouffe, el ideal de la sociedad democrática no puede encarnarse en una armonía cuasi-perfecta que deje fuera de la discusión aspectos esenciales de la vida en común:

Por tanto, la democracia no sólo está en peligro cuando hay un déficit de consenso sobre sus instituciones y de adhesión a los valores que representa, sino también cuando su dinámica agonística se ve obstaculizada por un consenso aparentemente sin resquicio [...] (1999: 18).

En efecto, un "exceso de consenso" puede lastrar y dinamitar la práctica democrática, y más cuando dicho exceso de consenso afecta a los aspectos y ámbitos más determinantes de nuestra existencia social, a saber, los principios organizativos de la vida económica. Si dichos principios, como pretende el neoliberalismo, están aquilatados en una esfera de indiscutibilidad y si no se puede, en suma, decidir ni disputar sobre ellos, la vida democrática se reduce a una mínima expresión.

Estaríamos hablando de un escenario en el que lo democrático, como ámbito de intervención popular en las decisiones políticas, emerge como un proceso obturado:

El "cierre de la política» ha sido señalado con voz de alarma por crecientes autores en los últimos años como intento de «tecnificar» cada vez más cuestiones de la vida pública sacándolas así del campo de lo discutible [...] (Errejón: 2011: 81).

Si una serie de principios, a saber, los postulados económicos ortodoxos, jamás entran en el ámbito de lo discutible asistimos entonces a una operación de naturalización absoluta de un determinado marco que, por ello mismo, jamás aparece como una opción política contingente impuesta frente a otras opciones posibles y probables. Precisamente se trata de anular esto último a través de una operación despolitizadora que conlleva, como bien señala Íñigo Errejón, una tecnificación de los asuntos colectivos. Podrá permitirse, en todo caso, una variación de parámetros a la hora de resolver técnicamente determinados asuntos (variación que, en cualquier caso, habrá de ser una mera dilucidación entre expertos y tecnócratas), pero lo que jamás será discutido (esto es, politizado) es el marco mismo.

Una intervención genuinamente política implicaría no ya discutir dentro de los límites de un determinado marco, sino discutir el propio marco. Este marco (eminentemente, el neoliberal) aparece como un consenso indubitable que jamás desciende a la arena de la confrontación de los proyectos políticos, y éstos últimos, cada vez más indiferenciados entre sí, apenas conforman ya una apariencia de verdadera democracia agonal, toda vez que dichos proyectos convergen progresivamente en lo sustancial. El "cierre político", que es un cierre democrático, aparece cuando ese marco ya no puede discutirse y deviene sentido común cristalizado y omnipresente.

La pluralidad agonística, como señala Mouffe, supone una condición imprescindible para el devenir de la vida democrática. Un orden genuinamente democrático no puede definirse por la naturalización de las fronteras de lo discutible ni concebir de manera inmovilista y esencialista los marcos discursivos, puesto que todo ha de estar sujeto a la confrontación y a la revocabilidad. Habermas pretendía situar la legitimidad del orden democrático en la concurrencia intersubjetiva dentro de un espacio dialógico ideal. Sólo los consensos cristalizados dentro de ese marco discursivo y comunicacional podrían albergar una legitimidad democrática (Habermas: 1998). Pero la propuesta habermasiana, manejando un concepto 
procedimental de democracia, adolece de un desplazamiento fraudulento de lo político, toda vez que el espacio pre-dialógico se halla repleto de múltiples asimetrías, contradicciones y opresiones que han de ser politizadas, esto es, que no pueden ser subsumidas en un consenso racional que camufle su irreductible conflictividad antagónica. El discurso eminentemente político ha de incardinarse, por lo tanto, en ese espacio pre-dialógico anterior a todo consenso habermasiano.

Frente a esa ilusión habermasiana, que hace de la apoteosis del consenso, alcanzado a través de procesos deliberativos dados en condiciones de máxima transparencia y ausencia de coacción, el ideal al que tiene que aspirar toda sociedad democrática, frente a esa ilusión, decíamos, la existencia de proyectos políticos adversarios es imprescindible para construir una situación democrática real. Una situación de consenso perfecto, en el que apenas nada es ya confrontado y discutido, puede incluso caracterizarse como orden semiautoritario que lo es, precisamente, por haber sido despolitizado, esto es, por haber erradicado de él la posibilidad de discutir y confrontar los elementos decisivos para el devenir de la vida colectiva (Mouffe: 2003: 114). Porque si las palabras y las metáforas con las que pensamos y experimentamos la realidad social también quedan previamente consensuadas entonces su significado queda ocluido y encuadrado de una vez por todas. Pero, precisamente, la disputa por el significado es una disputa eminentemente política y democrática.

Erradicar la dimensión inherentemente conflictiva de lo político, en aras de un exceso de consenso racional en la esfera pública, puede desembocar en la estabilización de unos límites muy estrechos para el marco de lo discutible o, lo que es lo mismo, la naturalización de un sistema cuasi-cerrado en el que múltiples temas y elementos determinantes para el desarrollo de la vida social quedan situados en un espacio de in-discutibilidad:

En una sociedad liberal democrática el consenso es, y será siempre, la expresión de una hegemonía y la cristalización de unas relaciones de poder. La frontera que dicho consenso establece entre lo que es legítimo y lo que no lo es, es de naturaleza política, y por esa razón debería conservar su carácter discutible (Mouffe: 2003: 64).

Debemos entender que todo consenso cristalizado ha de comprenderse siempre como una articulación contingente discutible, y no como la expresión de una racionalidad inmutable alcanzada de una vez por todas y de la que no cabe discrepar o disentir.

Una verdadera confrontación de proyectos, en los que se juega la disputa por la determinación de lo real, implica que esos marcos que el neoliberalismo pretende incuestionables queden también sumergidos en la discusión polémica y en la contingencia discursiva. Porque, además, una situación de creciente despolitización de la vida social, caracterizada por una ausencia de colisión agonal, degenera en una árida neutralidad técnica dentro de la cual ninguno de los aspectos esenciales de la existencia colectiva se discute y puede dar lugar, como de hecho ocurre, al surgimiento de identidades políticas (xenófobas, ultra-nacionalistas, chauvinistas) que promueven no ya un agonismo que disputa los marcos al "adversario" sino un antagonismo que busca en el límite aniquilar al "enemigo". La pretensión de construir un espacio social y cultural altamente despolitizado acaba provocando, paradójicamente, una recuperación perversa de la política que ahora ya concebirá las identidades en términos fuertemente esencialistas y que se moverá en unos términos exacerbados de aniquilación de las identidades políticas enemigas. Ésta última situación, que coincide con la definición ontológica de lo político dada por Carl 
Schmitt (1991: 56), podría acabar siendo, una vez más, el terrible efecto no previsto de esa anestesia neoliberal de la política. Porque lo político, en suma, siempre se abre hueco y acaba retornando de una u otra forma.

Jacques Rancière también incidía en esta misma cuestión:

El Estado «modesto» es un Estado que pone a la política como ausencia, que, en suma, se desprende de lo que no le atañe -el litigio del pueblo- [...] Hoy en día, el Estado se legitima al declarar imposible a la política. $Y$ esta demostración de imposibilidad pasa por la demostración de su propia impotencia. La posdemocracia, para poner al demos como ausencia, debe hacer lo mismo con la política, atenazada por la necesidad económica y la regla jurídica, con el riesgo de unir a uno y otra en la definición de una nueva ciudadanía en la que el poder y la impotencia de cada uno y de todos vienen a igualarse (1996: 139).

El Estado liberal, podemos interpretar a tenor de lo dicho, confluye en una impotencia de la política que se traduce, a la vez como efecto y como causa, en una ausencia del demos, toda vez que éste aparece como incapaz de intervenir activamente en la configuración de unos marcos definidos y delimitados por necesidades económicas imponderables e inmodificables. El propio Schmitt ya constataba que el pathos liberal había sido siempre inherentemente apolítico puesto que, en la práctica histórica, pretendió desplegar su proyecto a través de una creciente despolitización basada en la disolución (irreal, a la postre) de la conflictividad inherentemente política, esto es, construyendo un marco políticamente anestesiado de puras relaciones económicas determinadas por las reglas de la competencia comercial y mercantil (Schmitt: 1991: 98).

Schmitt comprendía que la ratio del parlamentarismo descansaba en el principio de la discusión pública, pero pudo detectar ya en 1923 que las grandes decisiones de las cuales dependía el destino de millones de personas no se tomaban con arreglo a la confrontación discursiva en la esfera pública parlamentaria sino que dichas decisiones se ejecutaban de manera creciente en comisiones político-económicas a espaldas del parlamento, cuyo funcionamiento iba quedando reducido a simulacro fementido y a pantomima teatral. Schmitt sabía que los detentadores de la economía privada, que él caracterizaba como "los dueños del poder real", determinaban el curso de las naciones y de los pueblos más allá de todo control o determinación parlamentaria (1996: 65). Pero si los principios que rigen la esfera del poder económico no pueden discutirse en público, pues la dinámica real de su funcionamiento transcurre por espacios extra-parlamentarios a través de lógicas que nunca pueden ser interrumpidas, reguladas o puestas en cuestión por la esfera política pública, entonces la razón de ser del orden democrático pierde sustancia y fundamento, toda vez que el ámbito real de decisión está allende sus fronteras. El auténtico soberano, en última instancia, es el poder económico privado.

La política misma, dentro de un proyecto económico liberal que llevara su lógica interna hasta sus últimas consecuencias, devendría mera gestión tecnocrática de un aparato económico que, como tematiza Polanyi, se desarrolla prácticamente como un proceso autonomizado y autorregulado desde un punto de vista institucional y emancipado desde todo punto de vista normativo y axiológico (2003: 121). La vida política, en semejante contexto, quedaría reducida al papel de mero apéndice gestor de unos procesos económicos que, absolutizados en una dinámica desprendida, en ningún caso están sometidos a fiscalización pública y control social. Milton Friedman, prócer tardío del neoliberalismo norteamericano de la Escuela de Chicago, también lo diría sin ambages: . 
El amplio uso del mercado reduce la sobrecarga que sufre el entramado social, ya que en todas las actividades que abarca hace innecesaria la conformidad. Cuanto más amplio sea el número de actividades cubiertas por el mercado, menor será el número de cuestiones en las que se requieren decisiones expresamente políticas y, por tanto, en las que es necesario alcanzar un acuerdo (1966: 41).

Lo político se diluye en los indiscutibles, inescrutables e incontrolables resultados producidos por el sistema de mercado omnipresente y omnisciente. El sistema de los mercados libres cubre sobradamente los ámbitos de "decisión" que han de configurar la parte más esencial de nuestra vida social. Siempre perteneció a la visión liberal del funcionamiento social el considerar que el orden económico más óptimo a la hora de distribuir toda la información relevante de la manera más extensa y eficaz es el que resulta de la espontaneidad de los millones de actores cuyo comportamiento individual espontáneo se guía únicamente a través de la señal de los precios que las mercancías van adquiriendo a cada momento dentro de un sistema de libre mercado generalizado (Hayek: 1997).

El litigio político, según se desprende de estos análisis, queda eliminado y sólo permanecen divergencias mínimas dentro de un marco intocable de soluciones técnicas. En este ámbito, que puede ser caracterizado como "posdemocrático", como veremos a continuación, la política misma emerge como impotencia precisamente porque la confrontación de proyectos ideológicos queda reducida a su más mínima expresión, toda vez que todos los "proyectos" aparentemente en liza quedan subsumidos en un mismo consenso técnico por medio del cual se establecen unos límites infranqueables que, precisamente por ser técnicos y apolíticos, nunca pueden ser intervenidos o decididos; ese marco es en sí mismo indecidible, precisamente por ser él mismo el marco constitutivo de toda decisión.

\section{Posdemocracia y dictadura tecnofinanciera}

En las antípodas de una democratización de la economía, o de una re-politización democrática de la misma, estamos caminando de una forma imparable hacia fórmulas eminentemente posdemocráticas, como señala Colin Crouch. Los grandes centros del poder económico acaparan la práctica totalidad de las decisiones reales que afectan a la vida de millones de seres humanos, en directo detrimento de los organismos políticos elegidos y fiscalizados democráticamente. "Las empresas no son simples organizaciones, sino más bien concentraciones de poder" (Crouch: 2004: 70). En el año 2003, y según indicaba el propio Banco Mundial, de las cien mayores potencias económicas mundiales 49 eran países y 51 corporaciones transnacionales (Navarro, Torres López: 2012: 27). Y el avance impertérrito de acumulación de poder por parte de estos conglomerados de la economía privada se halla íntimamente vinculado a los procesos desdemocratizadores que definen la situación que estamos tratando de desvelar. "El creciente poder político de las empresas sigue siendo el principal efecto del avance de la posdemocracia" (Crouch: 2004: 146). Aunque, corrigiendo la frase de Crouch, más bien habríamos de sostener que es la posdemocracia el principal efecto del avance del poder de la empresa privada, y ello a tenor de lo que el propio Crouch sostiene:

Si los dueños de una empresa multinacional no encuentran un régimen fiscal o laboral favorable a sus intereses en un determinado país, amenazarán con trasladarse a otro. Por tanto, tienen mayor acceso a los gobiernos y mayor capacidad de influencia en las políticas públicas que los ciudadanos de a pie [...] (2004: 55). 
De hecho, los organismos financieros internacionales, exigiendo ajustes estructurales a los gobiernos soberanos, se hacen de facto con la gobernanza de dichos países. Y, como consecuencia de dicho proceso, la ciudadanía política activa de los habitantes de dicho país queda desdibujada y mermada en su calidad democrática.

En tanto que las funciones que antes correspondían exclusivamente a los marcos jurídicos nacionales comienzan a desplazarse hacia centros de poder privado transnacional y organismos semiautónomos transfronterizos, podemos empezar a preguntarnos si los procesos de des-nacionalización conllevan irremediablemente fenómenos concomitantes de des-democratización, precisamente en tanto que las responsabilidades y prerrogativas que determinan el juego decisivo de la vida socioeconómica quedan transferidos a lugares que están más allá de la jurisdicción de los marcos democráticos nacionales. "Si la formación del mercado global de capitales representa una concentración de poder con capacidad para influir en las políticas económicas de los gobiernos nacionales y, por extensión, en sus otras políticas, entonces las normas que rigen estas posibilidades constituyen una de las cuestiones clave. Hoy los mercados financieros globales no sólo son capaces de emplear un poder coercitivo, sino que han producido una lógica que se integra a las políticas públicas nacionales y un conjunto de criterios que definen la política económica "adecuada»" (Sassen: 2007: 120). Y es por ello que, sin demasiado reparo, pudo decretarse el crepúsculo del Estado-nación o, en todo caso, su devenir en "unidad artificiosa" carente de todo instrumental capaz de desempeñar algún tipo de papel sustancial y determinante en el cosmos de una economía exponencialmente transfronteriza (Ohmae: 1997: 64).

Estamos hablando, en todo caso, de la emergencia de un nuevo paradigma de poder.

La independencia no es, desde luego, completa, y el capital no es todavía tan volátil como quisiera y como se esfuerza por ser. Aún hay que contar con factores territoriales -localesen la mayoría de los cálculos; el «poder fastidioso» de los gobiernos sigue, quizá, imponiendo irritantes limitaciones a su libertad de movimiento. Pero el capital se ha hecho extraterritorial, ligero, sin estorbos y desincrustado hasta un extremo sin precedentes, y el nivel de movilidad espacial que ya ha alcanzado es perfectamente suficiente para chantajear a los organismos políticos vinculados con el territorio para que se sometan a sus exigencias. La amenaza (incluso tácita y meramente sospechada) de cortar los lazos locales y trasladarse a otra parte es algo que todo gobierno responsable tiene que tratar con toda seriedad, tratando de determinar sus propias acciones en consecuencia. La política se ha convertido hoy en un tira y afloja entre la velocidad con que el capital puede moverse y la capacidad de «ralentización» de las instituciones locales, y son éstas las que tienen la sensación de estar librando una batalla imposible de ganar (Bauman: 2001: 36).

La política local ha de ser sumamente hospitalaria con el capital internacional, ha de plegarse lúbricamente a sus necesidades de movilidad y flexibilidad:

Sostengo que la soberanía se ha visto descentralizada y el territorio parcialmente desnacionalizado. Desde una perspectiva histórica más amplia, esto representaría una transformación en la articulación de soberanía y territorio, al igual que han marcado la formación del sistema del Estado moderno y del moderno sistema interestatal. Y eso, a su vez, implicaría una necesidad de ampliar el campo analítico dentro del que las ciencias sociales examinan algunos de estos procesos, lo que equivale a decir, la tendencia explícita o implícita a utilizar el Estado-nación como el marco abarcador de los procesos sociales, políticos y económicos (Sassen: 2001: 45). 
El Estado-nación, como fuente de una soberanía anclada territorialmente, va quedando difuminado en sus contornos, desinflado en su consistencia, palidecido en su capacidad de control, determinación e influencia, dando paso a una gobernanza transterritorial que articula una nueva soberanía cuyos límites vienen sostenidos y sancionados por la lógica económica de los mercados financieros internacionales. En este sentido, puede decirse que emerge una nueva tecnología del poder cuyo epicentro, a pesar de contar con Gobiernos y Estados, dimana de los centros económicos privados transfronterizos (Castro: 2010: 73).

En efecto, y como sigue apuntando Saskia Sassen, el concepto clásico de ciudadanía empieza a quedar reformulado en el contexto de un capitalismo global triunfante.

La formación de un mercado global de capitales representa una concentración de poder capaz de influir en la política económica nacional de los gobiernos y, por extensión, en otras políticas también. Estos mercados ejercen ahora las funciones de responsabilidad asociadas a la ciudadanía: pueden votar a favor o en contra de la política económica de los gobiernos; pueden obligar a los gobiernos a adoptar determinadas medidas y no otras. Los inversores "votan» con sus movimientos, entrando o saliendo de un país, a menudo con enormes cantidades de dinero. Aunque el poder de estos mercados es muy distinto al del electorado político, han emergido como una especie de electorado económico global transfronterizo, donde el derecho a votar se predica en la posibilidad de colocar capital (Sassen: 2001: 56).

Son los gestores del capital los nuevos y verdaderos "representantes políticos" de un orden mundial en el que ya las decisiones públicas decisivas no se toman, pues, en unos órganos de representación que han quedado desvencijados, obsoletos y desbordados. Hablamos, en suma, de una transferencia de soberanía nacional y popular a instancias no electas (Napoleoni: 2013).

Señalaban Michael Hardt y Antonio Negri el tránsito hacia una nueva forma de soberanía que, en el límite, terminaba por derruir la forma de soberanía que había prevalecido y determinado el curso de la edad moderna: "El Otro que podía delimitar un sí mismo soberano moderno se ha fragmentado y es indistinto; ya no hay un exterior que pueda delimitar el lugar de la soberanía" (2002: 180). En efecto, la nueva soberanía imperial, como ellos dan en denominarla, ya no tiene un centro localizado como fundamento, ya no reside en un lugar que delimita con un exterior, ya no se enfrenta a otras soberanías frente a las cuales adquiere sentido la propia; esta nueva forma de soberanía no tiene ni centro, ni lugar, ni exterior:

El espacio estriado de la modernidad construyó lugares que se basaban y participaban continuamente en un juego dialéctico con sus exteriores. El espacio de la soberanía imperial, en cambio, es uniforme [...] En este espacio uniforme del imperio, no hay ningún lugar del poder: éste está a la vez en todas partes y en ninguna. El imperio es una u-topía, es decir, un no lugar (Hardt, Negri: 2002: 181).

Ese nuevo poder omnipresente, panteísta, se desplaza a través del dominio mundial del mercado capitalista, asentado en un sistema de mercado totalizador que anula toda exterioridad y que, por ello mismo, va dejando de tener alteridad:

Es conveniente recordar aquí [...] que el mercado capitalista es una maquinaria que siempre funciona en contra de cualquier división entre lo interior y lo exterior. Las barreras y exclusiones obstaculizan su marcha; en cambio, prospera cuando puede abarcar cada vez más elementos dentro de su esfera [...] La realización del mercado mundial constituye el punto de llegada de esta tendencia. En su forma ideal, no existe lo exterior al mercado mundial: todo el planeta es su dominio. Por ello, podríamos emplear la forma del mercado mundial como modelo para comprender la soberanía imperial (Hardt, Negri: 2002: 180). 
Pero ese no-lugar, en verdad, alberga una potentísima fuerza como sujeto soberano. La escritora Viviane Forrester, con su estilo algo maximalista e histriónico, acertó plenamente en el diagnóstico:

Sin preocuparse demasiado por los Estados, frecuentemente más pobres que ellas, empantanados, puestos en tela de juicio, acusados, las potencias económicas pueden lanzarse a la acción, más libres, más motivadas, más ágiles, infinitamente más influyentes que aquéllos, sin preocupaciones electorales, responsabilidades políticas, controles [...] Se colocan por encima de todas las instancias políticas sin necesidad de tener en cuenta ninguna ética asfixiante [...] En el límite, en la más alta de sus esferas, donde el juego se vuelve imponderable, no tienen que responder por éxitos o fracasos ni jugarse por otra cosa que ellas mismas y sus transacciones, esas especulaciones sin término, ni otro fin que su propio movimiento (1997: 34).

La tutela ejercida por esas potencias económicas ubicuas sobre los Estados, que suelen cumplir un papel subalterno con respecto a ellas, desemboca en una gobernabilidad internacional construida desde una institucionalidad tecnocrática cuyo diktat no puede ser discutido por ninguna instancia democrática sustentada en una soberanía nacional-popular.

Esos "poderes salvajes", en efecto, sobrepasan todos los marcos legislativos y todos los órdenes constitucionales, y son éstos los que deben incluso reconstituirse y reescribirse para adaptarse a las exigencias inmodificables de aquéllos (Ferrajoli: 2011). Los poderes financieros apátridas, espacios de completa oscuridad y opacidad para el control democrático-popular, se convierten en el locus de la verdadera soberanía. Porque, como bien lo formulaba Jean Ziegler, asistimos a "la sobredeterminación de la soberanía popular por la racionalidad comercial y especulativa del capital financiero globalizado" (2003: 119). La llamada "financiarización" de la economía, un proceso por el cual la lógica absoluta de la autovalorización financiera ha venido desplegándose como una lógica autónoma y casi fantasmal desligada de la economía productiva, ha traído como consecuencia determinante una impotencia sustancial de los marcos de decisión sustentados en la soberanía popular, toda vez que las pautas generales de los ámbitos más decisivos de la vida socioeconómica han ido quedando externalizadas en manos de élites opacas no sujetas a control democrático alguno.

Nada explica mejor todo esto que la aniquilación de toda política genuinamente socialdemócrata, que acaba mostrando una patética porosidad indisimulada con respecto al discurso hegemónico neoliberal:

En pocas palabras y de un modo quizás paradójico, nada manifiesta mejor la racionalidad neoliberal que la evolución de las prácticas de los gobiernos que desde hace treinta años se dicen de izquierdas aunque lleven a cabo una política muy parecida a la de la derecha. Todo discurso «responsable», «moderno» y «realista», o sea, que participa de esa racionalidad, se caracteriza por la aceptación previa de la economía de mercado, de las virtudes de la competencia, de las ventajas de la mundialización de los mercados, de las exigencias ineludibles introducidas por la «modernización» financiera y tecnológica. La práctica disciplinaria del neoliberalismo se ha impuesto como un hecho dado, una realidad frente a la cual lo único que se puede hacer es adaptarse (Laval, Dardot: 2013: 236).

Se comprende perfectamente la operación puesta en juego:

El neoliberalismo es mucho más que una ideología partidaria [...] El neoliberalismo, cuando inspira políticas concretas, se niega a sí mismo como ideología porque es la razón misma [...] En suma, la gran victoria ideológica del neoliberalismo consistió en «desideologizar» las 
políticas que llevaba a cabo, hasta tal punto que ya no deben ser ni siquiera objeto de debate (Laval, Dardot: 2013: 245).

Como bien señalaba André Gorz, la justificación habitual del dogma que reza que no hay ninguna alternativa racionalmente concebible es la "globalización", un término revestido de neutralidad apolítica que pretende referirse a una evolución natural de la economía propiciada, principalmente, por la revolución de las tecnologías de la información y que oculta, en cambio, que el devenir mismo de esa globalización es un programa eminentemente político del gran capital que tiene como principal objetivo la estabilización de una ortodoxia económico-financiera a nivel cuasiplanetario (1998: 19).

Los parlamentos, en política económica, esto es, en aquello que más determina la contextura de nuestra fisonomía social, apenas pueden decidir nada, sólo aquello que ya ha sido determinado y decretado previamente por el poder fáctico y extraparlamentario del capital. La institucionalidad del capital financiero internacional es un no-lugar saturado de poder que se impone a unos Estados territorialmente anclados pero con prerrogativas en política económica cada vez menos autodeterminadas:

Sin base social ni constitución política, es un puro aparato que enuncia el derecho del capital globalizado. Poder sin sociedad, tiende a engendrar sociedades sin poder, pone en crisis a los Estados, desacredita la política [...] (Gorz: 1998: 24).

Si, como entendía Carl Schmitt, soberano es aquél que decide sobre el estado de excepción, hemos de preguntarnos quién detenta realmente la soberanía en el contexto nacional, regional e internacional que venimos dibujando (Schmitt: 2009: 13). Soberano es aquél que puede decidir, en un momento dado, interrumpir la vigencia de la norma jurídica y poner en suspensión las determinaciones del orden constitucional $\mathrm{o}$, en cualquier caso, soberano es aquél que puede actuar y decidir por encima o por debajo de dicha norma y de dicho orden. $Y$, hemos de consignar, quien puede ahora ocupar el lugar de ese soberano son las oligarquías financieras internacionales que someten a sus dictámenes a países enteros, determinando las políticas públicas de éstos, configurando sus normas jurídicas en asuntos comerciales, monetarios, medioambientales o laborales y, en muchos casos, interviniendo de facto en la redacción misma de su articulado constitucional (Monereo: 2014). En el caso concreto de la Unión Europea, en efecto, bien puede establecerse que toda su arquitectura ha sido diseñada con la casi exclusiva finalidad de garantizar un dominio absoluto del capital financiero, blindándose tratado tras tratado un diseño institucional que apenas dejaba margen de maniobra a los estados miembros de la Unión para aplicar alguna medida de genuina soberanía económica (Anderson: 2012: 79). Sin olvidar, por otro lado, que tal proceso ha traído como consecuencia una mayor dislocación regional dentro de la Unión, por la cual los países de la periferia han caminado aceleradamente hacia un estado de subdesarrollo y pérdida de soberanía a la par que las élites financieras vinculadas a las potencias del centro europeo han consolidado su hegemonía indiscutible. En ese sentido, la tiranía de las finanzas, a pesar de funcionar a través de una lógica internacional, no deja empero de quedar vinculada a determinados Estados nacionales que todavía ejercen un poder asimétrico con respecto a unos vecinos que, en muchos aspectos, son tratados como semicolonias. Además, la trampa del endeudamiento soberano de las naciones periféricas acentúa de una manera 
drástica su posición subalterna con respecto a las potencias centrales acreedoras (Álvarez Peralta, Luengo, Uxó: 2013).

Apuntemos, por todo ello, y como también señala Sassen, que no podemos entender de una manera simplista que el Estado ha sido sólo una víctima pasiva e inocente de este proceso, toda vez que en múltiples aspectos han sido los propios Estados los garantes de los "derechos" del capital global (2007: 70). Los postulados de laissez-faire, como bien había señalado Karl Polanyi, cobraron vigor y efectividad en la facticidad de la historia europea del siglo XIX únicamente gracias a la intervención activa, dirigida y consciente del poder político. El sistema de mercados autorregulados, la más inédita y exótica de las instituciones socioeconómicas habidas en la historia de las civilizaciones humanas, no es el estadio final de una evolución natural por fin liberada en la espontaneidad de la historia sino que, muy al contrario, se introdujo artificial y coactivamente, y por cierto con mucha dosis de brutalidad y violencia, a través de la imposición del poder político y estatal (Polanyi: 2003: 194). De igual modo, sucumbiremos a una mistificación fantasiosa si entendemos la llamada "globalización capitalista" contemporánea como un debilitamiento irremediable de los Estados, toda vez que lo que va quedando reducido a su mínima expresión es la función protectora y cohesionadora, la dimensión social, de dichos Estados a la vez que permanece incólume, si no reforzada, la función punitiva y represiva de los aparatos estatales, que constituyen una pieza esencial de la gobernanza neoliberal (Pilger: 2002: 37).

\section{Autoritarismo de mercado y fascismo financiero}

Ya Franz Neumann, yendo más allá de la retórica anti-estatista del liberalismo económico, había señalado con nitidez el insoslayable componente político de un Estado liberal que cumplió durante décadas un poderoso y activo papel de agente productor y dinamizador de los procesos socioeconómicos capitalistas:

\footnotetext{
El hecho de que también el liberalismo juzga que la inexistencia del Estado constituye su mayor virtud resulta tan evidente que no requiere prueba alguna. Según esta ideología, el Estado debe funcionar de modo imperceptible y tiene que ser realmente negativo. Sin embargo, quien identificase «negación» con "debilidad» resultaría víctima de una falacia histórica. El Estado liberal mostró siempre la fortaleza que le exigieron la situación política y social y los intereses de la sociedad. Sostuvo guerras y aplastó huelgas; con la ayuda de armadas poderosas protegió sus inversiones, con la de poderosos ejércitos defendió y extendió sus fronteras, y con la policía restableció «la paz y el orden». Fue un Estado fuerte precisamente en aquellas esferas de acción en que debió y quiso serlo (1968: 30).
}

Incluso cabe señalar que esas disposiciones mercantilizadoras y liberalizadoras no se limitaban a los países donde funcionaban modelos más o menos desarrollados de liberalismo político, ya que fueron aplicadas si cabe con mayor rotundidad en los principados y monarquías absolutas (Hobsbawm: 2011: 48).

En 1981 Hayek lo condensó en una fórmula franca y contundente, cuando valoraba las políticas ultraliberales en lo económico puestas en marcha por la dictadura militar chilena. "Mi preferencia personal se inclina a una dictadura liberal y no a un gobierno democrático donde todo liberalismo [económico] esté ausente" (Laval, Dardot: 2013: 185). Hayek no era partidario de rehabilitar viejos esquemas clásicos de laissezfaire, pues prefería decididamente un Estado fuerte ( $y$, si fuese necesario, políticamente dictatorial) pero que garantizase la libertad empresarial, antes que un gobierno políticamente democrático que decidiese intervenir legislativamente sobre la libertad de mercado y la libertad de comercio. 
Desde estas premisas se comprende que entregar una prerrogativa excesiva a la soberanía popular podía degenerar inevitablemente en formas de democracia totalitaria siempre y cuando dicha soberanía pretendiese legislar sobre la dinámica autónoma de la economía privada. Hayek entendía, en ese sentido, que hay un continuum evidente entre un impuesto progresivo sobre la renta y el gulag. Es lo que Walter Lippmann, el también escritor liberal, denominaba "evolución enfermiza" (1956: 80) de una democracia que, si era radical y jacobina, no podía constituirse en conciliación con un Estado liberal. El liberalismo económico llevado al extremo emerge aquí como una figura eminentemente demofóbica, pues un liberal consecuente quiere hacer prevalecer la libertad económica contra la regulación de cualquier forma de poder político, aunque éste sea un poder democrático y popular. Una tensión conflictiva ineludible se ha evidenciado históricamente entre democracia política y sistema de mercado autorregulado. En efecto, cuando éste último amplía irrestrictamente su extensión se producen fenómenos parejos de desdemocratización e, inversamente, cuando las clases populares y trabajadoras hacen valer su capacidad de controlar y determinar el poder político se establecen cortapisas institucionales y legislativas al libre despliegue del sistema de libre mercado. Esa pugna entre la institucionalidad democrática y la economía de mercado había atravesado diversas etapas, hasta llegar a la gran contrarrevolución neoliberal de los años setenta del siglo XX (Valderrama: 2013). El propio Hayek, una década antes de prestar su apoyo y su conocimiento al gobierno dictatorial de Pinochet, había alabado el régimen del dictador portugués Salazar, dando su beneplácito a la combinación perfecta de un Estado que era autoritario en el ámbito de las libertades políticas, civiles y sindicales y, a la vez, liberal en lo económico (Louçã: 2014). Desde los cenáculos del liberalismo económico y del anarcocapitalismo se propugna un "Estado mínimo", es cierto (Nozick: 1988). Un Estado mínimo despojado de toda función social pero que, en todo caso, esté lo suficientemente armado como para garantizar coactivamente la seguridad de la economía privada; porque la economía de libre mercado hubo de precisar, en el pasado para su emergencia y en el presente para su supervivencia, fuertes dosis de intervención gubernamental y poder policial que protegieran al orden liberal de las acechanzas de eso que Hayek denominaba "democracia ilimitada" (2010: 91).

El "fascismo financiero", como lo llama Boaventura de Sousa Santos, aparece como la forma más virulenta de los nuevos autoritarismos que sacuden la vida social contemporánea, toda vez que "su espacio-tiempo es el más refractario a cualquier intervención democrática" (1999: 25). La temporalidad política de este nuevo espacio de poder apenas puede ser manejada desde la institucionalidad democrática:

\footnotetext{
Este espacio-tiempo virtualmente instantáneo y global, combinado con el afán de lucro que lo impulsa, confiere un inmenso y prácticamente incontrolable poder discrecional al capital financiero: puede sacudir en pocos segundos la economía real o la estabilidad política de cualquier país. No olvidemos que de cada cien dólares que circulan cada día por el mundo sólo dos pertenecen a la economía real. Los mercados financieros son una de las zonas salvajes del sistema mundial, quizá la más salvaje. La discrecionalidad en el ejercicio del poder financiero es absoluta y las consecuencias para sus víctimas -a veces, pueblos enteros- pueden ser devastadoras (Sousa Santos: 1999: 25).
}

Asistimos a una recomposición en las relaciones políticas de dominación cuando el universo de las finanzas reduce a su más mínima expresión el control que sobre ellas pudieran ejercer instituciones democráticas y legislaciones sociales. Estas instituciones y estas legislaciones son sacrificadas al poder cada vez más omnímodo y autoritario de unos mercados financieros que, además de arruinar la economía real 
y la vida social de las gentes comunes, imponen su lógica con una naturalidad inapelable y aparentemente irreversible, estrechándose con ello de una manera alarmante todo margen de intervención pública y democrática en la delineación de la vida económica de la colectividad (Alonso Benito, Fernández Rodríguez: 2013). Esa lógica impuesta no se discute, no se delibera acerca de ella, y las fuerzas políticas mayoritarias asumen la inviolabilidad e inalterabilidad de dicho marco y asimilan, de igual modo, la absoluta necesidad de realizar los ajustes dictados por las tecnocracias financieras no sometidas a fiscalización democrática alguna.

Nos encontramos, en suma, con un proceso caracterizado por la desposesión económica de las grandes mayorías sociales que, y esto es decisivo, se acompaña a su vez de un proceso acelerado de des-empoderamiento político de dichas mayorías. Asistimos a la configuración de una nueva gobernanza que, desde el poder financiero, produce un nuevo ajuste disciplinario en la vida social. Este programa político de autoritarismo de mercado, que traslada todo el poder a las élites financieras, empezó a esbozarse ya en los años setenta, cuando la famosa Comisión Trilateral diagnosticó que demasiadas instancias civiles, sociales y jurídicas (sindicatos, legislaciones laborales, sistemas de seguridad social) distorsionaban el estricto funcionamiento libre y competitivo de los mercados y, por lo tanto, una nueva gobernanza (neo) liberal no podía sino abrirse a través de una trituración sin ambages de los viejos contratos sociales de posguerra que se fundamentaban en el Estado social y en la fuerte protección del mundo del trabajo (Crozier, Huntington, Watanuki: 1975). Uno de los autores de este informe, Michel Crozier, apostaba en otro trabajo, y no casualmente, por una "desinflación de la política" que coadyuvara a una disolución de las instituciones estatales mediadoras de la intervención política en los asuntos comunes (1992: 259). Este programa, por lo tanto, apuesta por una clara despolitización que, finalmente, se traduce en una des-democratización de la vida socioeconómica.

Tal vez hubo demasiada euforia a la hora de saludar sin ambages una nueva era caracterizada por un ocaso del "nacionalismo económico" que suponía, principalmente, el sometimiento de las naciones a las fuerzas centrífugas de la economía mundial (Reich: 1993). Desde múltiples instancias se saludó el proceso de la hiperglobalización económica como un gigantesco y benéfico proceso integrador por el que, dentro de cada país, la política encogía a la vez que la economía mejoraba (Friedman: 2000: 104). O, mejor dicho, desde tales premisas se entendía que la economía mejoraba precisamente porque la política encogía. Pero tales apologías precipitadas pronto dieron lugar a tensiones inevitables, hasta el punto de poder decir con Dani Rodrik que "no podemos perseguir simultáneamente democracia, autodeterminación nacional y globalización económica” (Rodrik: 2012: 20). No puede soslayarse, por lo tanto, que asistimos a un choque inevitable entre política democrática e hiperglobalización económico-financiera, precisamente porque ésta exige sin remisión un encogimiento de todas aquellas dimensiones de la institucionalidad política nacional que puedan suponer un excesivo coste para los inversores internacionales. Los mercados financieros internaciones promueven un programa abiertamente des-democratizador. $Y$ no hay, en ese sentido, demasiadas alternativas. Las democracias, frente al poder devastador de los mercados globales, tienen derecho a proteger su propia urdimbre social y, por lo tanto, las exigencias radicales de una economía financiera mundializada y salvaje son del todo incompatibles con una nación que pretenda construir unos estándares socioeconómicos que protejan mínimamente las condiciones materiales de vida de las mayorías sociales. 


\section{Desactivar la lógica de lo normal, cambiar el sentido común de época}

David Harvey esbozó las líneas maestras de una virulenta contraofensiva liberal cuyo movimiento empieza en la década de 1970, y que ha dado lugar a un nuevo resurgimiento de la tiranía de los mercados:

[...] el neoliberalismo se ha tornado hegemónico como forma de discurso. Posee penetrantes efectos en los modos de pensamiento, hasta el punto de que ha llegado a incorporarse a la forma natural en que muchos de nosotros interpretamos, vivimos y entendemos el mundo (2007: 7).

No podemos sino pensar, al escuchar estas palabras de Harvey, en aquella "mentalidad de mercado" que el propio Polanyi denunciara como obsoleta en los años treinta, y ante la cual proponía la extensión de principios políticos democráticos a todos los aspectos de la vida social, incluidos las funciones económicas, enunciando con ello que la dogmática económica imperante podía y debía discutirse políticamente, quebrando de esa manera la naturalización de los principios económicos de la ortodoxia liberal (1994: 251). Esta mentalidad de mercado, que sólo nos permite entender la vida social en términos de mercado, si bien colapsó dramáticamente en la tercera década del siglo $X X$ reaparecería, girando la historia de Occidente sobre sí misma, con los últimos estertores del keynesianismo, allá por los años setenta, y con el comienzo de la agonía un Estado del bienestar que aceleraría su descomposición con más fuerza si cabe de la mano de un proyecto neoliberal triunfante (Albarracín: 1993).

Es verdad que la proposición "desactivar la lógica de lo normal" puede parecer una fórmula meramente retórica, pero creemos que puede servirnos como principio heurístico para mostrar un problemática cuya importancia creemos es de primer orden. Según hemos ido viendo a lo largo de estas páginas, esa "lógica de lo normal" viene estructurada y predefinida por los parámetros de la doctrina económica ortodoxa, presentada como la economía universal y natural, atributos que la revisten de tecnicidad indiscutible, precisamente porque los principios de esta ortodoxia económica acaban constituyéndose en los contornos de lo posible, en las fronteras de lo pensable y los límites de lo imaginable.

Arremeter contra ese estatuto incuestionable del programa económico ortodoxo es empezar a desbloquear ese cierre discursivo y político. En efecto, es un movimiento ineludible para empezar a contravenir el discurso naturalizador de la economía de mercado, que la presenta como insuperable. Sólo desactivando la potencia de dicho discurso es posible, a su vez, empezar a concebir otra institucionalización de la vida humana, ajena a la lógica corrosiva, criminal y suicida de los "mercados omnipotentes". Porque, precisamente, esa omnipotencia impertérrita se ha identificado con la "normalidad" de nuestros días. Desactivar la mentalidad de mercado, que prefigura la lógica de lo normal, se convierte por lo tanto en una condición imprescindible para desnaturalizar (que, en este caso, equivale a repolitizar) el sentido común de época permeado de mentalidad de mercado, deshaciendo todas las evidencias acumuladas en dicho sentido común en la era llamada neoliberal.

Cuando Francis Fukuyama proyectaba, en 1992, un horizonte histórico universal determinado por el triunfo definitivo del sistema democrático encuadrado en los marcos incontestables de liberalismo económico, en lo que él denominaba "revolución liberal mundial", estaba diciendo algo importante, por mucho que ahora 
nos pueda parecer risible su tesis del final de la historia (1992: 75). Lo que nos estaba diciendo es, en efecto, que habíamos alcanzado una fase que bien podía darse por definitiva, toda vez que la imaginación de los hombres ha agotado todas las alternativas al sistema liberal, emergiendo dicho sistema como una forma de organización social que no admite más que modificaciones internas que no ponen en cuestión su estructura básica. "Hoy, en cambio, nos cuesta imaginar un mundo que sea radicalmente mejor que el nuestro, o un futuro que no sea esencialmente democrático y capitalista" (Fukuyama: 1992: 83). Lo decisivo es, precisamente, ese bloqueo de la imaginación. Esta tesis, que todavía permanece viva, sostiene que no podemos imaginar un mundo que sea distinto al configurado por la extensión universal del sistema de mercado (y compuesto por formas políticas democráticas que no interrumpan en ningún sentido los principios del liberalismo económico) y al mismo tiempo mejor. La batalla universal de la historia había decantado una normalidad social definitivamente determinada por las institucionalidad del libre mercado, una normalidad blindada y ante la cual las posibilidades de problematización aparecían prácticamente canceladas para la imaginación y la praxis política.

En ese sentido, transformar el sentido común de época, por usar términos de Antonio Gramsci, resultará crucial para poder cortocircuitar esta "normalidad" aquilatada hegemónicamente en nuestra visión del mundo. "Una filosofía de la praxis sólo puede presentarse inicialmente en actitud polémica y crítica, como superación del modo de pensar precedente y del pensamiento concreto existente (o del mundo cultural existente). Es decir, sobre todo, como crítica del "sentido común» [...]" (1997: 14). Si el neoliberalismo se hizo cuerpo también, y quizás principalmente, en la mentalidad popular es ahí donde han de incidir las prácticas contra-hegemónicas, deshaciendo evidencias que el propio neoliberalismo había blindado con apariencia de naturalidad incuestionable e inmodificable. La consolidación de un "aparato ideológico", por seguir utilizando un léxico gramsciano, podría propiciar la construcción de un terreno cultural amplio dentro del cual se dan los límites de lo que puede ser conocido y realizado y, a su vez, introduce la encarnación de una específica moral asociada a una particular visión del mundo (Gramsci: 1997: 46). Es en ese medio en el que los hombres otorgan sentido a su relación con los otros hombres y significado a su posición dentro del la trama social. Y si todo este sentido común de época ha estado durante décadas dominado hegemónicamente por los postulados del neoliberalismo entonces, claro está, una praxis contra-hegemónica habrá de dar la batalla cultural e ideológica en este mismo terreno, deconstruyendo y desactivando la naturalización del sentido común neoliberal (Mouffe: 2003: 23).

Para empezar a contrarrestar esa fantasía terrible construida por los doctrinarios del liberalismo económico, y que presupone que la realidad económica es una realidad técnica, un procedimiento neutro exterior al campo político de lo discutible y lo decidible, sólo queda la alternativa de combatir una despolitización que es, dicho sea de paso, la operación más intensamente ideológica concebible. En efecto, y como bien apunta Slavoj Zizek, esa despolitización de lo económico supone una operación por medio de la cual los axiomas de la teoría económica ortodoxa se aceptan como una realidad incuestionable e indiscutible que delimita las fronteras mismas de lo posible y de lo imaginable:

La gran novedad de nuestra época post-política del «fin de la ideología» es la radical despolitización de la esfera de la economía: el modo en que funciona la economía [de mercado] se acepta como una simple imposición del estado objetivo de las cosas [...] La única manera de crear una sociedad en la que las decisiones de alcance y riesgo sean fruto 
de un debate público entre todos los interesados, consiste, en definitiva, en una suerte de radical limitación de la libertad del capital, en la subordinación del proceso de producción al control social, esto es, en una radical re-politización de la economía (Zizek: 2007: 110).

Este diagnóstico habría de traducirse en un disciplinamiento de los mercados que tuviera como objetivo la aniquilación de la omnipotencia tiránica de los mismos para evitar, perentoriamente, que el destino de la vida colectiva se vea sometido a su dinámica emancipada y descontrolada. En ese sentido, puede estar muy en lo cierto Walden Bello cuando habla de la necesidad de emprender un cierto proceso de "desglobalización", entendiendo por tal una democratización de la economía que implique un retorno de ésta a los mecanismos de control localmente asentados (2002: 188).

Pero tienen razón Laval y Dardot cuando advierten que la hegemonía absoluta de la racionalidad neoliberal, en lo discursivo y en lo institucional, no sólo pone en entredicho la "tercera fase" de las olas democratizadoras, eso es, la fase en la que quedan consolidados los derechos sociales y laborales de la ciudadanía, sino que el avance irrestricto de la racionalidad liberal arruina, además, las primeras consolidaciones formalmente democráticas en el orden civil y jurídico. Por ello, tampoco la crítica marxista a la "democracia formal" expresa con suficiencia la gravedad del asunto, toda vez que incluso los propios fundamentos de una democracia meramente liberal (sin entrar siquiera en el asunto del desmantelamiento del Estado social) están quedando interrumpidos. La gobernanza neoliberal no es, por lo tanto, democrática en la forma y antidemocrática en los hechos. El problema es más hondo, puesto que ya no es democrática en absoluto, ni siquiera en un sentido genuinamente formal (Laval, Dardot: 2013: 396). Y cuando un sistema económico desquiciado e incontrolable empieza a colisionar incluso con el modelo democrático más estrechamente formal y procedimental asistimos, entonces, a una modificación sustancial de todas las coordenadas políticas precedentes.

\section{Referencias bibliográficas:}

AlbarRaCín, Jesús (1993) La larga noche neoliberal. Políticas económicas de los ochenta, Barcelona, Icaria.

Alonso BeNITO, Luis Enrique; Fernández Rodríguez, Carlos Jesús (2013) "Debemos aplacar a los mercados: el espacio del sacrificio en la crisis financiera actual", en Vínculos de Historia, № 2, pp. 97-119.

Álvarez Peralta, Ignacio; Luengo, Fernando; Uxó, Jorge (2013) Fracturas y crisis en Europa, Buenos Aires, Eudeba.

ANDERSON, Perry (2012) El nuevo viejo mundo, Madrid, Akal.

ARENDT, Hannah (1998) Los orígenes del totalitarismo, Madrid, Taurus.

BAUMAN, Zygmunt (2001) La sociedad individualizada, Madrid, Cátedra.

BELLO, Walden (2002) "La contraofensiva global", en Mundo, S. A. Voces contra la globalización, Barcelona, Ediciones de la Tempestad.

BRACHER, Karl Dietrich (1983) Controversias de historia contemporánea sobre fascismo, totalitarismo y democracia, Barcelona, Alfa.

CASTRO, Rodrigo (2010) "Neoliberalismo y gobierno de la vida", en Hacer vivir, dejar morir. Biopolítica y capitalismo, Madrid, Catarata.

Crouch, Colin (2004) Posdemocracia, Madrid, Taurus. 
CrozIeR, Michel; Huntington, Samuel; Watanuki, Joji (1975) The crisis of democracy: report on the governability of democracies to the Trilateral Commission, New York, University Press.

Crozier, Michel (1992) Estado modesto, estado moderno: estrategia para el cambio, México, Fondo de Cultura Económica.

ERREJÓN, Íñigo (2011) "La construcción discursiva de identidades populares", en Viento Sur, 114, Enero, pp. 75-84.

FerRAJOLI, Luigi (2011) Poderes salvajes. La crisis de la democracia constitucional, Madrid, Trotta.

ForRESTER, Viviane (1997) El horror económico, México, Fondo de Cultura Económica.

FriedMAN, Milton (1966) Capitalismo y libertad, Madrid, Rialp.

Friedman, Thomas L. (2000) The Lexus and the olive tree, New York, Anchor Books.

FUKUYAMA, Francis (1992) El fin de la Historia y el último hombre, Barcelona,

Planeta.

GORZ, André (1998) Miserias del presente, riqueza de lo posible, Buenos Aires,

Paidós.

GrAMSCI, Antonio (1997) El materialismo histórico y la filosofía de Benedetto Croce, Buenos Aires, Nueva Visión.

HABERMAS, Jürgen (1998) Facticidad y validez. Sobre el derecho y el Estado democrático de derecho en término de teoría del discurso, Madrid, Trotta.

HARDT, Michael; Negri, Antonio (2002) Imperio, Barcelona, Paidós.

HARVEY, David (2007) Breve historia del neoliberalismo, Madrid, Akal.

HAYEK, Friedrich (1997) "El uso del conocimiento en la sociedad", en Reis, 80, pp. 215-226.

- (2010) Principios de un orden social liberal, Madrid, Unión Editorial.

HOBSBAWM, Eric (2011) La era del capital. 1848-1875, Barcelona, Crítica, 2011.

LAVAL, Christian; Dardot, Pierre (2013) La nueva razón del mundo. Ensayo sobre la sociedad neoliberal, Barcelona, Gedisa.

LIPPMANN, Walter (1956) La crisis de la democracia occidental, Barcelona, Editorial Hispano Europea.

LoUÇÃ, Francisco (2014) "Una carta de Hayek a Salazar y los neoliberales autoritarios, a propósito de la Unión Europea y el Estado Social", en Sin Permiso.

MONEREO, Manolo (2014) Por Europa y contra el sistema euro, Barcelona, El Viejo Topo.

MoUfFE, Chantal (1999) El retorno de lo político, Barcelona, Paidós.

- (2003) La paradoja democrática, Barcelona, Gedisa.

NAPOLEONI, Loretta (2013) Democracia en venta. Cómo la crisis económica ha derrotado la política, Barcelona, Paidós.

NAVARRO, Vicenç; TORRES LóPEZ, Juan (2012) Los amos del mundo. Las armas del terrorismo financiero, Barcelona, Espasa.

NeUMANN, Franz (1968) "El cambio en la función de la ley en la sociedad moderna", en El Estado democrático y el Estado autoritario, Buenos Aires, Paidós.

Nozick, Robert (1988) Anarquía, Estado y utopía, Buenos Aires, Fondo de Cultura Económica.

OHMAE, Kenichi (1997) El fin del estado-nación, Santiago de Chile, Andrés Bello.

PETRAS, James (1999) "Democracia y capitalismo. Transición o neoautoritarismo", en Herramienta, № 11, Septiembre.

PILGER, John (2002) "La impotencia del Estado", en Mundo, S. A. Voces contra la globalización, Barcelona, Ediciones de la Tempestad. 
POLANYI, Karl (2003) La gran transformación, México, Fondo de Cultura Económica. - I (1994) "Nuestra obsoleta mentalidad de mercado", en Cuadernos de Economía, Universidad Nacional de Colombia, 14 (20), pp. 249-266.

RANcière, Jacques (1996) El desacuerdo. Política y filosofía, Buenos Aires, Nueva Visión.

REICH, Robert (1993) El trabajo de las naciones, Madrid, Javier Vergara.

RODRIK, Dani (2012) La paradoja de la globalización, Barcelona, Antoni Bosch.

SASSEN, Saskia (2001) ¿Perdiendo el control? La soberanía en la era de la globalización, Barcelona, Bellaterra.

- (2007) Una sociología de la globalización, Buenos Aires, Katz.

SCHMITT, Carl (1991) El concepto de lo político, Madrid, Alianza, 1991.

- (1996) Sobre el parlamentarismo, Madrid, Tecnos.

- (2009) Teología política, Madrid, Trotta.

SOUSA SANTOS, Boaventura (1999) Reinventar la democracia, reinventar el Estado, Madrid, Sequitur.

VALDERRAMA, Paola (2013) "Contrarrevolución fascista y democracia neoliberal. El golpe y la transición en Chile desde una perspectiva polanyiana”, en Pléyade, № 11, Enero-Junio, pp. 13-36.

ZIEGLER, Jean (2003) Los nuevos amos del mundo, Barcelona, Destino.

ZIZEK, Slavoj (2007) En defensa de la intolerancia, Madrid, Sequitur. 